\title{
High-efficiency Algorithm for the Most Unfavourable Load Case Combinations of Multilayered Frame-Type Wharf Structure
}

\author{
Linjian WU, Li GUAN, Xueli JU, Mingwei LIU*, Yuanfei MA, Erdi ABI
}

\begin{abstract}
The wharf, which was built in the Three Gorges Reservoir of China, is constructed as a layered frame-type structure for adapting to large water level fluctuations that exceed $30 \mathrm{~m}$. These large fluctuations cause the frame-type structure to exhibit a considerably higher number of load case combinations than traditional marine highpiled wharfs. To estimate the most adverse combined internal force and the corresponding unfavourable load case combinations of significant components for multilayered frame-type wharf structures in the Three Gorges Reservoir of China, a high-efficiency algorithm is developed in this study. This algorithm can skilfully transform the computational mode of load case combinations into a matrix operations process by computer programming. By applying the proposed algorithm, the number of load case combinations for eight significant components of frame-type wharf, including piles, columns, beams, braces and berthing components, are resolved to a total of 21 from the original quantity of more than six billion. This high-efficiency algorithm can provide powerful technical support for evaluating the bearing capability of multilayered frame-type wharfs in the Three Gorges Reservoir of China.
\end{abstract}

Keywords: high-efficiency algorithm; most unfavourable load combinations; multilayered frame-type wharf; SAP 2000; Three Gorges Reservoir of China

\section{INTRODUCTION}

Multilayered frame-type wharfs under large water level fluctuations, as shown in Fig. 1, are composed of many significant components, such as all-straight piles of large diameters, columns, longitudinal and transverse beams, braces, panels, berthing components, and other ancillary facilities of wharfs. The Cuntan and Guoyuan Ports in the Three Gorges Reservoir of China are representative port engineering projects that adopt multilayered frame-type wharfs [1-4], as shown in Fig. 2. Due to the unique hydrologic situations in the Three Gorges Reservoir [3], the water level fluctuations can exceed $30 \mathrm{~m}$ [5]. Consequently, wharfs are often constructed in a layered mooring arrangement and multipoint berthing operation mode for adapting to these large water level fluctuations. Due to the particularity for the structural style of this frame-type wharf under large water level fluctuations, some significant external load cases, such as the impact force and mooring force, have a large number of possible load locations, which would cause this frame-type structure to exhibit a considerably higher number of load case combinations than traditional marine high-piled wharfs with a monolayer mooring arrangement and berthing operation mode [5]. In the past, the most unfavourable load case combinations for this type of structure are usually confirmed by engineers' experiences during the initial design process. However, a general empirical method must be implemented using substantial personal subjectivity; as a result, some incorrect phenomena regarding mistakes and negligence frequently occur.

Therefore, it is extremely vital to develop a reasonable and high-efficiency algorithm to determine the most unfavourable load case combinations of multilayered frame-type wharfs in the Three Gorges Reservoir of China. However, few studies have considered similar conditions at the international level due to the specificity of the hydrologic situations and the unique structural style of these structures. For example, the water level fluctuations of any of the navigationally developed rivers (such as the Rhine, Danube, Elbe and Oder Rivers in Germany; the
Loire and Rhone Rivers in France; the Dnieper, Volga, and Ural Rivers in Russia; and the Mississippi River in America, etc.) are nearly all less than $10 \mathrm{~m}[6,7]$. Despite these data, some sources in the international literature have presented similar studies of other structures. For example, load combination has been investigated on long-span bridges and super-tall buildings, as well as when determining the overall design loads for power plants. $\mathrm{Vu}$ et al. [8] presented a convenient and effective finite element-based method for coupled flutter analysis of longspan bridges. The self-excited forces per unit span of a bridge deck, which arise from the interaction between the smooth wind flow and the bridge, including the lift force, drag force and pitching moment, are expressed as a linear combination of nodal displacement and velocity. Naderian et al. [9] proposed an integrated finite strip discretization scheme for evaluating the static analyses of long-span cable-stayed bridges under combinations of various external loads, such as wind and vehicle loads that act on different positions. Chen et al. [10] proposed a framework for fatigue analysis of a long-span suspension bridge under the combined effect of railway, highway, and wind loading. Yoo et al. [11] discussed detailed procedures for obtaining buckling lengths of steel girder members in longspan cable-stayed bridges by a modified numerical eigenvalue analysis. During this procedure, the external loads were considered by combining the dead load (selfweight and attachments) and live load (lane load). Kim et al. [12] investigated wind load combinations for super-tall buildings, for which the parallel wind, crosswind and torsional loads would occur simultaneously in time and space in reality. By using a simplified four-column reference model, evaluations in the time-domain were discussed, and the combination rules based on the concept of the combination factor were presented in this literature. Six [13] developed different load cases for power plants and for combining these cases to determine the overall design loads according to the use of the Minimum Design Loads for Buildings and Other Structures (ASCE 7-10) [14]. In this study, the majority of general load cases and specific loads (ash load, unbalanced pressure forces, and 
boiler loads, etc.) with their load case combinations were synthetically discussed.

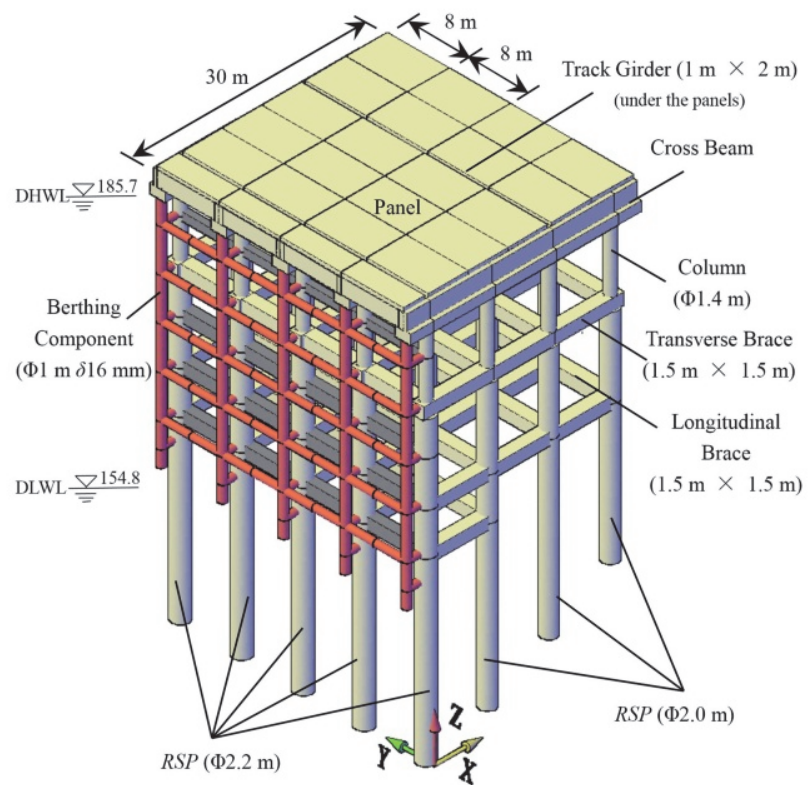

Figure 1 Three-dimensional illustration of the frame-type wharf under large water level fluctuations in the Three Gorges Reservoir of China (DHWL: design high water level; DLWL: design low water level; RSP: rock-socketed pile; units for each component are shown in figure)

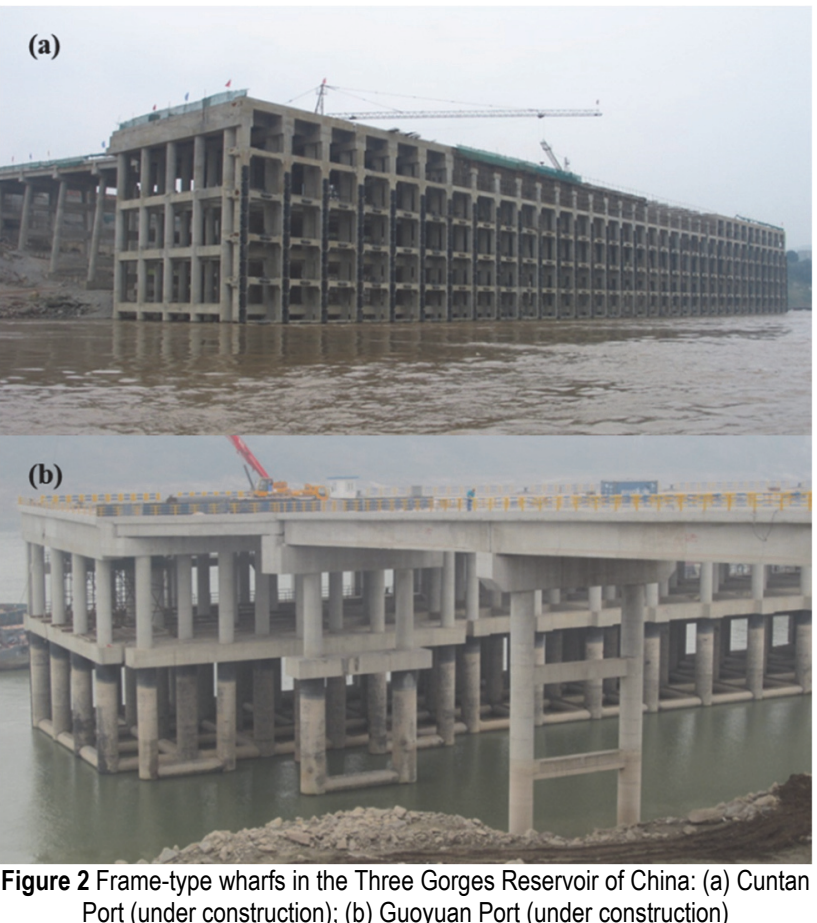

This paper established a high-efficiency algorithm for estimating the most adverse combined internal force results and the corresponding unfavourable load case combinations of different important components for multilayered frame-type wharfs based on the premise of previous research results [6-14]. This algorithm employs the load combination principles of high-pile wharf structures [15] to determine the most adverse combined values of internal force and their corresponding load case combination results for significant components of multilayered wharf structures in the Three Gorges Reservoir of China.

\section{CASE STUDY \\ 2.1 Project Profile}

A representative project of a multilayered frame-type wharf was performed as a case study. This frame-type wharf is located in the upper reaches of the Yangtze River in the Three Gorges Reservoir of China, where the water level fluctuations can reach nearly $30 \mathrm{~m}[5,16]$. Fig. 1 shows a three-dimensional (3D) chart of this case. The width of the structure's front platform is $30 \mathrm{~m}$, and the separation distance between two transverse bent frames is $8 \mathrm{~m}$.

The pile foundations are based on a large-diameter straight reinforced concrete rock-socketed pile $(R S P)$; the diameter of each front-side pile is $2.2 \mathrm{~m}$ and the diameter of each back-side pile is $2.0 \mathrm{~m}$. Reinforced concrete columns with a diameter of $1.4 \mathrm{~m}$ are erected over the piles. From a functional or constructional point of view, the "piles" and "columns" are the significant components that are employed to mainly withstand vertical loads. The essential difference between these two components is their various diameter sizes. The section type of the cross beams is an inverted $\mathrm{T}$ shape. The longitudinal beams may include boundary beams, general carlings and track girders, and their section forms are rectangular, with the following sizes (width $\times$ height): boundary beam $(0.6 \mathrm{~m} \times 2.0 \mathrm{~m})$; general carling $(0.8 \mathrm{~m} \times 2.0 \mathrm{~m})$; and track girder $(1.0 \mathrm{~m} \times 2.0 \mathrm{~m})$. The reinforced concrete composite slabs are treated as panels that are tiled over the longitudinal beams, and the thickness of each slab is $0.45 \mathrm{~m}$. Three layers of longitudinal and transverse braces are set up throughout the substructure; the physical dimensions of their rectangle sections are $1.5 \mathrm{~m} \times 1.5 \mathrm{~m}$. DA-A500H-type rubber fenders are installed on the steel berthing components $(\varnothing 1.0 \mathrm{~m}, \delta=$ $16 \mathrm{~mm})$. The significant components of this frame-type wharf structure in the Three Gorges Reservoir of China, such as RSP, column, beam, brace, and berthing components, are jointed with each other via cast-in-place concrete; thus, every joint among these components would be regarded as rigid joints in a structural finite element model (FEM).

For this paper's case study, two types of $R S P(\varnothing 2.2 \mathrm{~m}$ and $\varnothing 2.0 \mathrm{~m}$ ), column, cross beam, track girder, transverse brace, longitudinal brace, and berthing component are treated as eight significant components, including the frame-type wharf structure. According to the extension directions of different components, these eight significant components are divided into vertical, transverse, and longitudinal types, which contain the vertical components of two types of RSP, column, and berthing components; the transverse components of the cross beam and transverse brace; the longitudinal components of the track girder and the longitudinal brace.

\subsection{Finite Element Model (FEM)}

The internal force results of the significant components under every load case that separately acts on a frame-type wharf must be solved to provide essential data for the following algorithmic operation. This paper regards 
the complex wharf structure as a 3D space-frame model for finite element analysis [17]. Each structural segment may contain five transverse bent frames, and the deformation seams are applied to slice the adjacent two segments. Therefore, the load transmission between the two independent objects can be reasonably disregarded.

Any existing structural finite element analysis software can be applied to establish the 3D FEM of a frame-type wharf structure [18]. For this paper's study, Structure Analysis Program 2000 (SAP2000) [19] is selected to calculate the internal force results of every significant component of a frame-type wharf's FEM. During the establishment of the FEM by SAP 2000, the significant components, such as piles, columns, beams, braces, and berthing components, of this structure are simulated by three-node linear elastic beam elements in a space (B32) of uniform section. The thin-plate elements are employed to simulate the panels. Moreover, the boundary constraint conditions are operated in accordance with the hypothetical wedge spot theory. The depth positions of the hypothetical wedge spots for different piles of this paper's FEM are determined by Reese and Vanimpe [20], and six degrees of freedom (DOFs) are restrained at the wedge spots' locations. Fig. 3 shows the 3D FEM of the wharf with five bent frames.

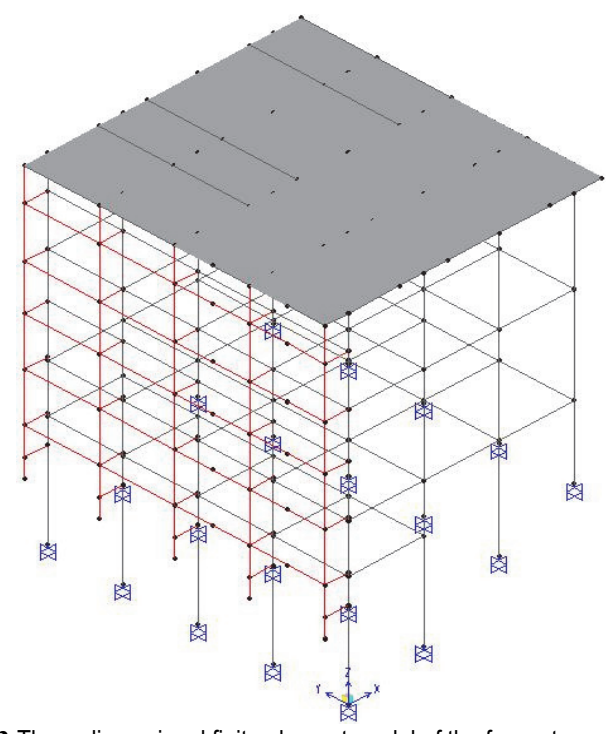

Figure 3 Three-dimensional finite element model of the frame-type wharf with five bent frames (units: $m$ )

\subsection{Load Cases}

\subsubsection{Permanent Load}

The permanent load is the dead load $(D L)$ of the entire structure, which can be regarded as one load case; the density of the reinforced concrete is $\gamma_{R C}=25 \mathrm{kN} / \mathrm{m}^{3}$, and the density of the steel is $78.5 \mathrm{kN} / \mathrm{m}^{3}$.

\subsubsection{Variable Load}

\section{(1) Cargo Load:}

The cargo load $(C L)$ is treated as the surface pressures that act on each panel. The main surface areas of one structural segment comprise 20 lattices. In terms of Tab. 5.1.1-3 of the Chinese standard [21], the $C L$ value for this paper's case wharf is recommended as $30 \mathrm{kPa}$.
Fig. 4 shows the distribution of the initial $20 C L$ cases. The number of final $C L$ cases should be comprehensively evaluated based on the entire heaped load mode, as the CLs may simultaneously appear on multiple lattices. Therefore, the number of final $C L$ cases can be calculated as follows:

$\underbrace{C_{20}^{0}}_{\text {No } C}+\underbrace{C_{20}}_{C \text { on } 1 \text { lattice }}+\underbrace{C_{20}^{2}}_{C \text { on } 2 \text { lattices }}+\ldots+\underbrace{C_{20}^{19}}_{C \text { on } 19 \text { lattices }}+\underbrace{C_{20}^{20}}_{C \text { on } 20 \text { lattices }}(1)$ $=1048576$

\begin{tabular}{||c|c|c|c||}
\hline$C L 16$ & $C L 11$ & $C L 6$ & $C L 1$ \\
\hline$C L 17$ & $C L 12$ & $C L 7$ & $C L 2$ \\
\hline$C L 18$ & $C L 13$ & $C L 8$ & $C L 3$ \\
\hline$C L 19$ & $C L 14$ & $C L 9$ & $C L 4$ \\
\hline$C L 20$ & $C L 15$ & $C L 10$ & $C L 5$ \\
\hline
\end{tabular}

Figure 4 Distributions of initial cargo load cases (CL: cargo load; units: kPa)

\section{(2) Portal Crane Load:}

According to the Tab. C.0.1 of the Chinese standard [21], the portal crane with its specification of Mh-40-45, for which the maximum rated lifting capacity of this type portal crane is $40 \mathrm{t}$, is considered this case wharf's hoisting machinery. This paper considers one portal crane operation on the wharf's platform. Both the outrigger span and the distance between the two tracks of the portal crane are 12 $\mathrm{m}$. During the structural finite element analysis, the portal crane load is considered for a moving load that acts on two track girders. Eight wheels are installed in each outrigger of this crane type, and the portal crane load $(P C L)$ cases are classified into three types according to Tab. C.0.3 of the standard [21], as shown in Fig. 5.

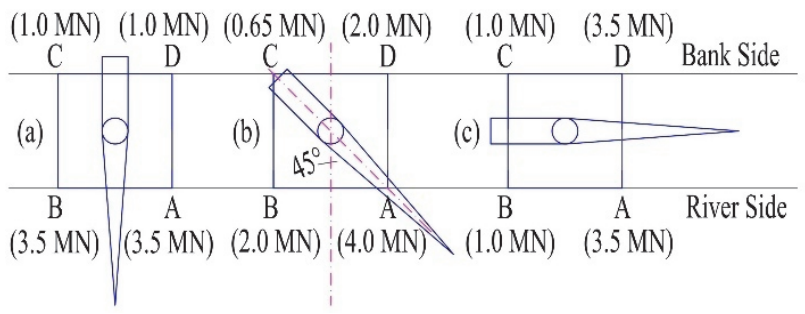

Figure 5 Three types of portal crane load cases (PCL: portal crane load; units: MN): (a) PCL 1, (b) PCL 2, and (c) PCL 3

\section{(3) Ship Load:}

The standard values of impact force $(I F) F_{I F}$ and mooring force $(M F) F_{M F}$ are evaluated by the standard [21], and $F_{I F}=1000 \mathrm{kN}$ and $M_{I F}=845 \mathrm{kN} \cdot \mathrm{m}$ based on the maximum berthing velocity, namely, $V_{n}=0.2 \mathrm{~m} / \mathrm{s} . F_{M F}=$ $436 \mathrm{kN}$ according to the design water flow velocity $V=2.5$ $\mathrm{m} / \mathrm{s}$ and the offshore wind velocity $V_{w}=22 \mathrm{~m} / \mathrm{s}$. During the process of structural static finite element analysis for frame-type structures, the impact force and mooring force cases are treated as concentrated forces that act on different 
corresponding node positions of berthing components and bollards within the FEM of the wharf structure in Fig. 3. The number of $I F$ and $M F$ cases are determined according to the large water level fluctuations, which range from $154.8 \mathrm{~m}$ to $185.7 \mathrm{~m}$ in this area of the Three Gorges Reservoir of China, as shown in Fig. 1. Fig. 6 shows the acting positions of all $24 \mathrm{IF}$ cases and the $12 \mathrm{MF}$ cases considering the symmetry of the structure. $I F 1, I F 2, I F 9$, $I F 10, I F 17$, and $I F 18$ are defined as the impact forces of the high water level $(H W L)$, and $M F 1, M F 2, M F$ 7, and $M F 8$ are defined as the mooring forces of the HWL. IF 3 $\sim \operatorname{IF} 5, I F 11 \sim I F$ 13, and $I F 19 \sim \operatorname{IF} 21$ denote the impact forces of the middle water level $(M W L)$, and $M F 3 \sim M F 5$, and $M F 9 \sim M F 11$ denote the mooring forces of the $M W L$. IF $6 \sim I F 8, I F 14 \sim I F 16$, and IF $22 \sim I F 24$ are the impact forces of the low water level $(L W L)$, and $M F 6$ and $M F 12$ are the mooring forces of the $L W L$.

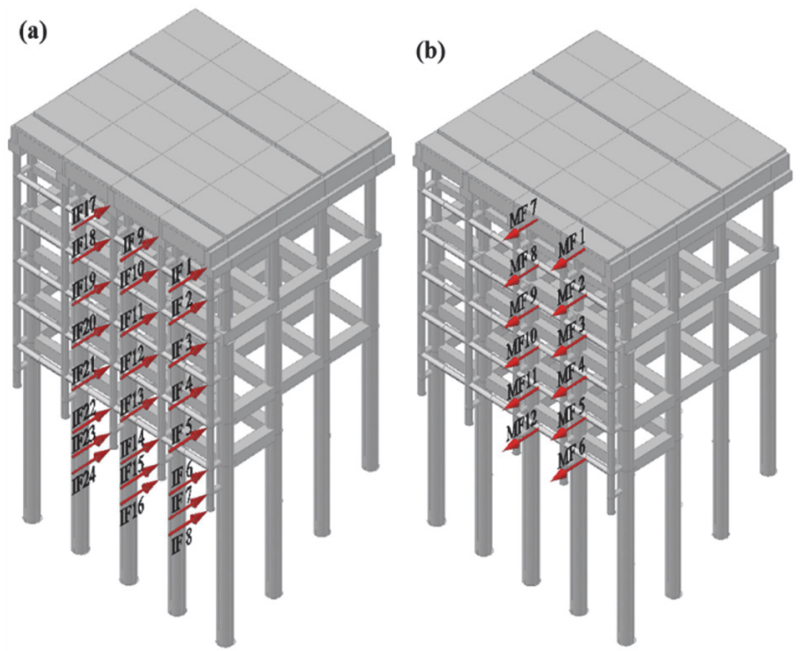

Figure 6 Load cases of the (a) impact force; (b) mooring force (IF: impact force; MF: mooring force; units: kN)

\subsection{Load Combination Schemes}

Impact forces on wharf structure only appear during the process of ships berthing, when the mooring forces are acting on the wharf and ships have already berthed completely. In addition, when the portal cranes are being operated, ships have already been berthed, which means that the impact forces cannot be combined with portal crane loads. Thus, two principles must be followed when combining load cases:

(1) The impact force cannot be combined with the mooring force; and

(2) The impact force cannot be combined with the portal crane load at the operation status.

The load combination schemes $(L C S s)$ are classified into two types based on these principles:

(1) LCS 1: Dead load + cargo load + ship load (mooring force or impact force);

(2) LCS 2: Dead load + cargo load + portal crane and mooring force (individual portal crane load or portal crane load and mooring force, as denoted by the portal crane and mooring force $(P C M F)$ ).

The number of $L C S 1$ and LCS 2 instances are shown in Tab. 1. The number of load case combinations for only one component in a multilayered frame-type wharf can be statistically calculated as $38797312+41943040=80$
740352. The wharf includes eight significant components, and the most unfavourable internal force combined values of each component include the axial force, shear force and bending moment. In addition, the shear force and bending moment of each component have the worst results for the 2 and 3 -axis sections (refer to the cross beam example in Fig. 7), whereas each axis contains the most unfavourable positive and negative values. The number of load case combinations for the wharf structure's eight components is equal to $80740352 \times 8 \times$ $10=6459228160$, details are shown in Tab. 2.

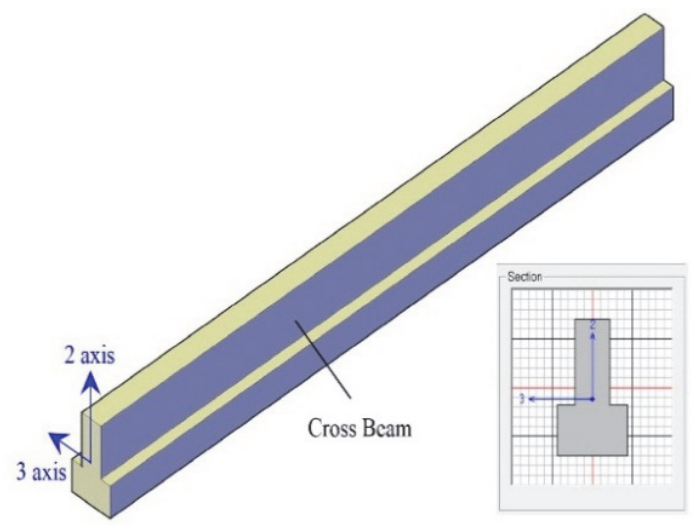

Figure 7 2- and 3-axis sections for cross beam (units: $\mathrm{m}$ )

\begin{tabular}{|c|c|c|c|c|c|}
\hline \multicolumn{2}{|c|}{$\begin{array}{c}\text { Load cases } \\
\text { LCS } 1\end{array}$} & $\begin{array}{c}\text { Quantities } \\
\text { LCS } 1\end{array}$ & \multicolumn{2}{|c|}{ Load cases } & $\begin{array}{c}\text { Quantities } \\
\text { LCS } 2\end{array}$ \\
\hline \multicolumn{2}{|c|}{$D L$} & 1 & \multicolumn{2}{|c|}{$D L$} & 1 \\
\hline \multicolumn{2}{|c|}{$C L$} & 1048576 & \multicolumn{2}{|c|}{$C L$} & 1048576 \\
\hline \multirow{3}{*}{$\begin{array}{c}S L \\
(M F \\
\text { or } I F)\end{array}$} & no $S L$ & 1 & \multirow{3}{*}{$\begin{array}{c}P C M F \\
(P C L \text { or } \\
P C L \& \\
M F)\end{array}$} & $\begin{array}{c}\text { no } \\
P C M F\end{array}$ & 1 \\
\hline & $M F$ & 12 & & $P C L$ & 3 \\
\hline & IF & 24 & & $\begin{array}{c}P C L \& \\
M F\end{array}$ & $3 \times 12=36$ \\
\hline \multicolumn{2}{|c|}{ Aggregate } & 38797312 & \multicolumn{2}{|c|}{ Aggregate } & 41943040 \\
\hline
\end{tabular}
LCS: load combination scheme; $D L$ : dead load; $\boldsymbol{C L}$ : cargo load; SL: ship load; $M F$ : mooring force; $I F$ : impact force; $P C M F$ : portal crane load and mooring force; $\boldsymbol{P C L}$ : portal crane load.

Table 2 Number of load case combinations for eight significant components of the wharf

\begin{tabular}{|c|c|c|c|c|}
\hline \multicolumn{4}{|c|}{ Types } & Quantities \\
\hline \multicolumn{4}{|c|}{ Single component } & 80740352 \\
\hline \multicolumn{4}{|c|}{ Number of components } & 8 \\
\hline \multirow{11}{*}{$\begin{array}{c}\text { Internal } \\
\text { force }\end{array}$} & \multirow{2}{*}{\multicolumn{2}{|c|}{$\begin{array}{l}\text { Most unfavourable } \\
\text { axial force } P\end{array}$}} & Positive $(+)$ & 1 \\
\hline & & & Negative $(-)$ & 1 \\
\hline & \multirow{4}{*}{$\begin{array}{c}\text { Most } \\
\text { unfavourable } \\
\text { shear } \\
\text { force } V\end{array}$} & \multirow{2}{*}{2 axis } & Positive $(+)$ & 1 \\
\hline & & & Negative (-) & 1 \\
\hline & & \multirow{2}{*}{3 axis } & Positive $(+)$ & 1 \\
\hline & & & Negative $(-)$ & 1 \\
\hline & \multirow{4}{*}{$\begin{array}{c}\text { Most } \\
\text { unfavourable } \\
\text { bending } \\
\text { moment } M\end{array}$} & \multirow{2}{*}{2 axis } & Positive $(+)$ & 1 \\
\hline & & & Negative (-) & 1 \\
\hline & & \multirow{2}{*}{3 axis } & Positive $(+)$ & 1 \\
\hline & & & Negative $(-)$ & 1 \\
\hline & \multicolumn{3}{|c|}{ Amount } & 10 \\
\hline \multicolumn{4}{|c|}{ Aggregate } & 6459228160 \\
\hline
\end{tabular}

\subsection{Implementation Procedures}

(1) General idea:

This paper is devoted to developing a reasonable and high-efficiency algorithm to determine the most adverse combined internal force results and the corresponding unfavourable load case combinations of the significant eight components installed in multilayered frame-type wharfs. The core concept for this proposed algorithm is that 
a large amount of internal force results (axial force, shear force, or bending moment) for various significant components within a frame-type wharf structure, which are estimated under the various external load cases separately being acted upon, are combined and superposed with each other in terms of the standard load combination principles using matrix operations; subsequently, the aforementioned combined internal force results are compared with each other to determine the most adverse combined internal force results and their corresponding unfavourable load case combinations for different components of the frametype wharf structure.

(2) Specific steps:

The specific implementation procedures for assessing the most unfavourable results of one component of the considered wharf are described as follows:

Table 3 Results of the internal force integration of one component of frame-type wharf

\begin{tabular}{|c|c|c|c|c|c|c|c|c|c|c|c|c|}
\hline \multirow[b]{2}{*}{$E N$} & \multirow[b]{2}{*}{$S N$} & \multicolumn{5}{|c|}{$L P_{1}$} & $\ldots$ & \multicolumn{5}{|c|}{$L P_{n}$} \\
\hline & & $L C_{1}^{1}$ & $\ldots$ & $L C_{1}^{d_{1}}$ & $\ldots$ & $L C_{1}^{m_{1}}$ & $\ldots$ & $L C_{n}^{1}$ & $\ldots$ & $L C_{n}^{d_{n}}$ & $\ldots$ & $L C_{n}^{m_{n}}$ \\
\hline \multirow[t]{2}{*}{$e_{1}$} & $s_{1}$ & $F_{1,1}$ & $\ldots$ & $F_{1, d_{1}}$ & $\ldots$ & $F_{1, m_{1}}$ & $\ldots$ & $\left.F_{1,\left(1+\sum_{k=1}^{n-1} m_{k}\right.}\right)$ & $\ldots$ & ${ }_{1,}^{F}\left(d_{n}+\sum_{k=1}^{n-1} m_{k}\right.$ & $\ldots$ & ${ }_{1,\left(\sum_{k=1}^{n} m_{k}\right)}$ \\
\hline & $\ldots$ & $\ldots$ & $\ldots$ & $\ldots$ & $\ldots$ & $\ldots$ & $\ldots$ & $\ldots$ & $\ldots$ & $\ldots$ & $\ldots$ & $\ldots$ \\
\hline \multirow{3}{*}{$e_{i}$} & $\ldots$ & $\ldots$ & $\ldots$ & $\ldots$ & $\ldots$ & $\ldots$ & $\ldots$ & $\ldots$ & $\ldots$ & $\ldots$ & $\ldots$ & $\ldots$ \\
\hline & $s_{j}$ & $F_{j, 1}$ & $\ldots$ & $F_{j, d_{1}}$ & $\ldots$ & $F_{j, m_{1}}$ & $\ldots$ & $F_{j,}^{F}\left(1+\sum_{k=1}^{n-1} m_{k}\right.$ & $\ldots$ & ${ }^{F},\left(d_{n}+\sum_{k=1}^{n-1} m_{k}\right.$ & $\cdots$ & $F_{j,\left(\sum_{k=1}^{n} m_{k}\right)}$ \\
\hline & $\ldots$ & $\ldots$ & $\ldots$ & $\ldots$ & $\ldots$ & $\ldots$ & $\ldots$ & $\ldots$ & $\ldots$ & $\ldots$ & $\ldots$ & $\ldots$ \\
\hline$\ldots$ & $\ldots$ & $\ldots$ & $\ldots$ & $\ldots$ & $\ldots$ & $\ldots$ & $\ldots$ & $\ldots$ & $\ldots$ & $\ldots$ & $\ldots$ & $\ldots$ \\
\hline \multirow[b]{2}{*}{$e_{a}$} & $\ldots$ & $\ldots$ & $\ldots$ & $\ldots$ & $\ldots$ & $\ldots$ & $\ldots$ & $\ldots$ & $\ldots$ & $\ldots$ & $\ldots$ & $\ldots$ \\
\hline & $s_{b}$ & $F_{b, 1}$ & $\ldots$ & $F_{b, d_{1}}$ & $\ldots$ & $F_{b, m_{1}}$ & $\ldots$ & $F_{b},\left(1+\sum_{k=1}^{n-1} m_{k}\right)$ & $\ldots$ & $b_{,}\left(d_{n}+\sum_{k=1}^{n-1} m_{k}\right.$ & $\ldots$ & $F_{b,\left(\sum_{k=1}^{n} m_{k}\right)}$ \\
\hline
\end{tabular}

$E N$ : element number; $S N$ : section number; $L P$ : load pattern; $L C$ : load case; units: $\mathrm{kN}$ for axial force and shear force, $\mathrm{kN} \cdot \mathrm{m}$ for bending moment.

Step one: 3D finite element analysis for the wharf structure. The 3D FEM of this structural segment (Fig. 3) is established by SAP 2000 to solve for the internal forces (axial force, shear force and bending moment) for each component in every separate load case.

Step two: Internal force matrix integration. All internal force data for each component are integrated based on Tab. 3 to generate the internal force matrix $M_{I F}$ using the algorithm program. In Tab. 3, EN and $S N$ denote the element number and section number, respectively, for each component of the wharf FEM; $L P$ denotes the load pattern; $L C$ denotes the load case, and each $L P$ may consist of many $L C s$. $F$ denotes the internal force values for this significant component, including the axial force, shear force and bending moment; $a$ is the number of finite elements of this component; $e_{i}$ represents the finite element $i$ of this component, $i=1,2, \ldots, a ; b$ corresponds to the number of sections of this component; $s_{j}$ represents section $j$, which is included in $e_{i}, j=1,2, \ldots, b ; L P_{n}$ denotes load pattern $n$ contained in $m_{n}$ load cases, $n \geq 1 ; m_{n}$ represents the number of load cases in $L P_{n}, m_{n} \geq 1$; and $L C_{n}^{d_{n}}$ denotes load case $d_{n}$ in $L P_{n}, d_{n}=1,2, \ldots, m_{n}$. Note that the summation of subscripts indicates a different internal force or moment under a certain load case that acts on the wharf structure.

For this wharf case, $M_{I F}$ consists of five types of load pattern matrixes: the dead load matrix $\boldsymbol{D L}$, portal crane

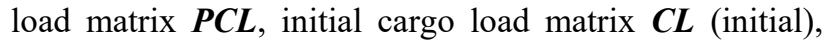
mooring force matrix $\boldsymbol{M F}$ and impact force matrix $\boldsymbol{I F}$. Different columns of $\boldsymbol{M}_{\boldsymbol{I F}}$ or load pattern matrixes are defined as the load case subvectors; the number of load case subvectors is one for $\boldsymbol{D L}$, three for $\boldsymbol{P C L}, 20$ for $\boldsymbol{C L}$ (initial), 12 for $\boldsymbol{M F}$ and 24 for $\boldsymbol{I F}$, in terms of the previously mentioned descriptions, which indicates that the internal force matrix $\boldsymbol{M}_{I F}$ contains 60 load case subvectors. Therefore, the internal force matrix, load pattern matrixes and their load case subvectors can be expressed as follows:

$$
\left[\boldsymbol{M}_{\boldsymbol{I F}}\right]_{b \times 60}=\left[[\boldsymbol{D} \boldsymbol{L}]_{b \times 1}[\boldsymbol{P} \boldsymbol{C}]_{b \times 3}[\boldsymbol{C}]_{b \times 20}^{i n i}[\boldsymbol{M F}]_{b \times 12}[\boldsymbol{I F}]_{b \times 24}\right]
$$

Step three: Final $\boldsymbol{C L}$ matrix, ship load matrix, and portal crane and mooring force matrix integration. The final cargo load matrix $\boldsymbol{C L}$ (final) can be integrated by the combination and superposition of the different subvectors of $\boldsymbol{C L}$ (initial) according to the descriptions in Section 2.3.1 (1). The number of load case subvectors is 1048576 for $\boldsymbol{C L}$ (final), thus, the load pattern matrix of $\boldsymbol{C L}$ (final) is expressed as $[\boldsymbol{C L}]_{b \times 1048576}^{\text {final }}$. Moreover, the ship load matrix $\boldsymbol{S} \boldsymbol{L}$ and the portal crane and mooring force matrix $\boldsymbol{P C M F}$ are generated according to Tab. 1 . The number of load case subvectors is 37 for $\boldsymbol{S L}$ and 40 for $\boldsymbol{P C M F}$; the load pattern matrix of the two cases is expressed as follows: $[\boldsymbol{S L}]_{b \times 37}$ and $[\boldsymbol{P C M F}]_{b \times 40}$, respectively.

Step four: Combination matrix integration. The combination matrix $\boldsymbol{L} \boldsymbol{C} \boldsymbol{C}$ of $\boldsymbol{L C S} 1$ and $\boldsymbol{L C S} 2$ can be integrated by the combination and superposition of the subvectors within the matrixes of $[\boldsymbol{D L}]_{b \times 1},[\boldsymbol{P C} \boldsymbol{L}]_{b \times 3}$, $[\boldsymbol{C L}]_{b \times 1048576}^{\text {final }},[\boldsymbol{S L}]_{b \times 37}$ and $[\boldsymbol{P C M F}]_{b \times 40}$ by this paper's algorithm using the loop statements and based on the principles of the load combination in Section 2.4. The form of the load combination matrixes is expressed as follows:

LCS 1:

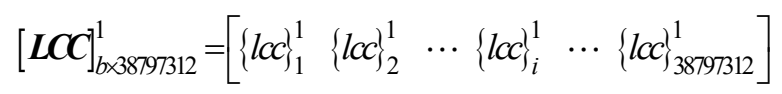

LCS 2:

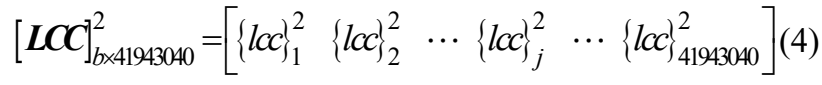


where $\{l c c\}_{i}^{1}$ and $\{l c c\}_{j}^{2}$ represent the combined and superimposed internal force results of $L C S 1$ and $L C S$, respectively; $i=1,2, \ldots, 38797312$; and $j=1,2, \ldots$, 41943040.

Step five: Comparison and recording of results. The combined internal force results including in the vectors $\{l c c\}_{i}^{1}$ and $\{l c c\}_{j}^{2}$ within Eq. (3) and Eq. (4) are compared with each other based on this paper's algorithm to determine the most unfavourable positive and negative internal force values included in the load combination matrixes $\boldsymbol{L} \boldsymbol{C} \boldsymbol{C}^{1}$ and $\boldsymbol{L} \boldsymbol{C} \boldsymbol{C}^{2}$, respectively. Subsequently, the most unfavourable positive results obtained for $\boldsymbol{L} \boldsymbol{C} \boldsymbol{S}^{1}$ are compared with those of $\boldsymbol{L} \boldsymbol{C} \boldsymbol{S}^{2}$ to determine the maximum positive internal force for this component. Similarly, the most adverse negative values for $\boldsymbol{L} \boldsymbol{C} \boldsymbol{S}^{1}$ are compared with those of $\boldsymbol{L} \boldsymbol{C} \boldsymbol{S}^{2}$ to confirm the minimum negative internal force for this component. Further, the absolute values of the previously mentioned maximum positive internal force results and minimum negative values are compared to determine the most unfavourable absolute values of internal force for this significant component. Moreover, the corresponding most unfavourable load case combinations for this component would be simultaneously recorded in terms of this paper's algorithm.

Step six: Output of results. If the calculations for all components of the wharf structure have been completed, the final outputted results include the following data: the most adverse combined absolute values of internal force (axial force, shear force and bending moment) and the corresponding most unfavourable load case combinations for these significant components of the wharf structure. Ultimately, the previously mentioned contents can be realized step by step using computer programming based on this paper's algorithm.

\subsection{Algorithm Flow and Calculation Results}

Fig. 8 shows the algorithm flow, which is consistent with Section 2.5. For this paper's case study, the final results are determined by programming based on the algorithm flowchart and shown in Tab. 4, where the symbols $N, Q$ and $M$ denote the axial force, shear force and bending moment, respectively, in the second column of Tab. 4.

\subsection{Results Analysis and Discussion}

This study explores whether the most unfavourable combined absolute internal force results for the components, which are determined by this paper's developed algorithm, are accurate and reasonable. The most unfavourable load case combinations, which correspond to the most adverse absolute values of internal force for the components, are employed as the external load cases to act on the FEM of the frame-type wharf. Subsequently, the most unfavourable internal force values of these components are calculated by structural finite element analysis and applied for a comparison with those from this proposed algorithm. As shown in Tab. 4, the most adverse combined absolute values of internal force for the components (third column of Tab. 4), which are obtained using the proposed algorithm, correspond well with the results from the previously mentioned structural finite element analysis process (fifth column of Tab. 4) for the most unfavourable load case combinations (fourth column of Tab. 4) that act on the FEM of the wharf structure. These findings validate the accuracy, reasonableness and feasibility of the algorithm developed in this paper.

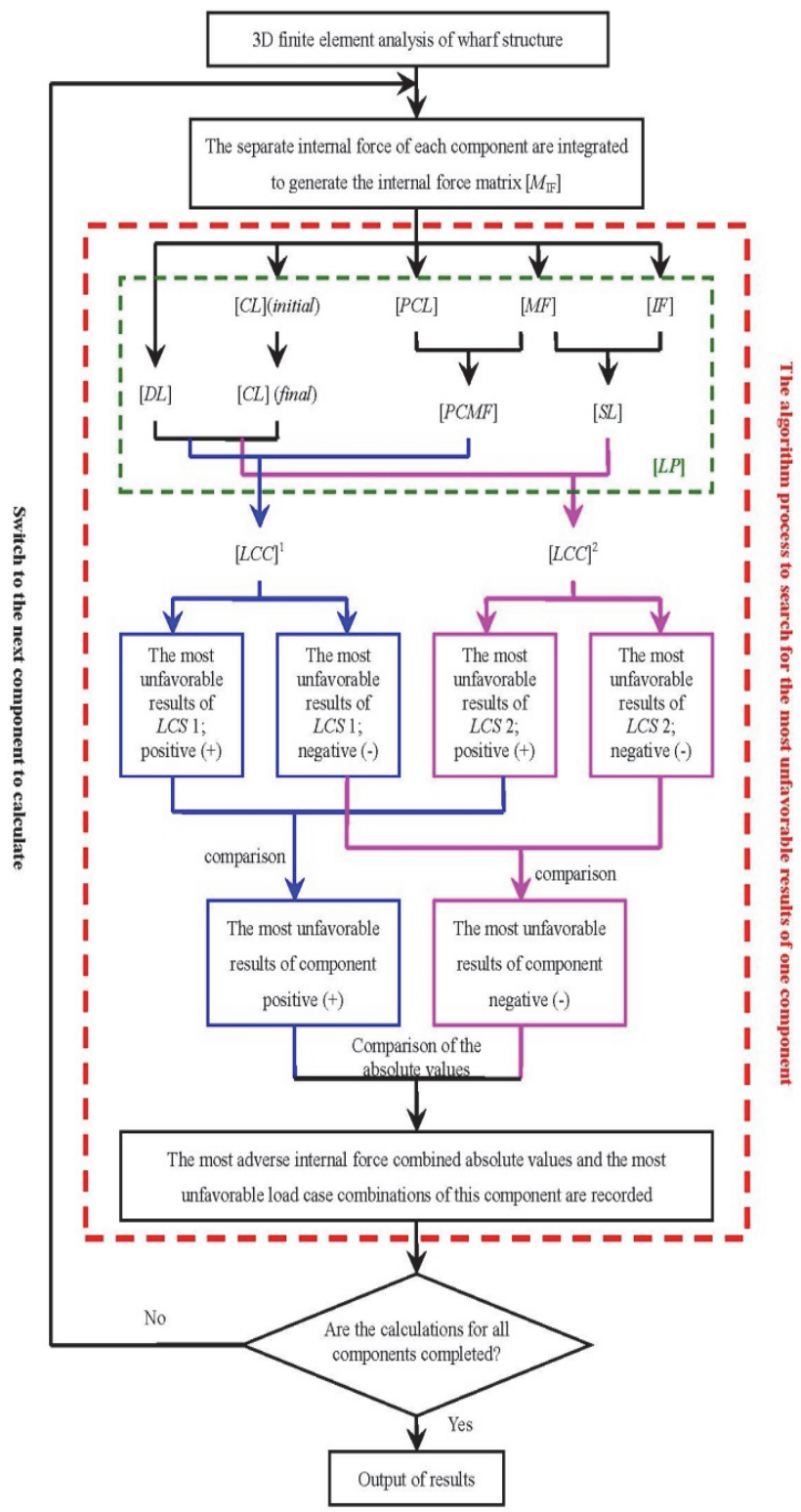

Figure 8 Algorithm flow chart (DL: dead load; $C L$ : cargo load; $P C L$ : portal crane load; MF: mooring force; IF: impact force; PCMF: portal crane load \& mooring force; SL: ship load; LP: load pattern; LCC: load case combination; LCS: load combination scheme

Moreover, the determination coefficient $\left(R^{2}\right)$, root mean square error (RMSE) and mean absolute error (MAE) related to the most adverse combined internal forces of the components are determined as the performance criteria for this paper's proposed algorithm [22]. Based on the results of the most adverse combined internal forces obtained by this paper's algorithm and the FEM, the $R^{2}, R M S E$, and $M A E$ are calculated as $0.9999,0.0069$, and 0.0039, respectively. It is seen that the algorithm developed by this paper's investigation achieves a considerable performance in calculating the most adverse absolute values of internal 
force and the corresponding most unfavourable load case combinations for the components.

The final results in Tab. 4 indicate that the highefficiency algorithm enables a certain number of the most unfavourable load case combinations for these eight significant components of multilayered frame-type wharf to be solved as a set of 21 from the original quantities (exceed six billion), which significantly reduce the workload of the wharf structure design. Moreover, the computational time required for one certain component may be approximately 25 - 30 min CPU time along the algorithm flow developed by this paper. However, if the traditional approach, which is consistent with the original complete combinations by manpower, is adopted to determine the most unfavourable combined internal force values and their corresponding load case combinations for significant components, the time consumed is incredible and unimaginable. Consequently, the algorithm proposed by this paper can dramatically improve the computational efficiency, and it is reasonable to consider this algorithm highly efficient.

Table 4 Final results of different significant components of the wharf structure

\begin{tabular}{|c|c|c|c|c|}
\hline Components & Internal force & $\begin{array}{l}\text { Internal force results } \\
\text { by algorithm }\end{array}$ & Load case combinations & $\begin{array}{l}\text { Internal force results } \\
\text { by FEM }\end{array}$ \\
\hline \multirow{3}{*}{$\begin{array}{c}R S P \\
(\varnothing 2.2 \mathrm{~m})\end{array}$} & $N$ & 12809.36 & $D L+C L 3,4,5,8,9,10,13,14,15,18,19,20+P C L 1+M F 7$ & 12809.36 \\
\hline & $Q$ & 1072.38 & $\begin{array}{l}D L+C L 2,3,4,5,7,8,9,10,12,13,14,15,17,18,19,20+ \\
I F 24\end{array}$ & 1072.38 \\
\hline & $M$ & 2363.68 & $D L+C L 5,10+I F 8$ & 2363.68 \\
\hline \multirow{3}{*}{$\begin{array}{c}R S P \\
(\varnothing 2.0 \mathrm{~m})\end{array}$} & $N$ & 11283.84 & $D L+C L($ all $)+P C L 1+M F 12$ & 11283.84 \\
\hline & $Q$ & 288.21 & $D L+C L 2,3,4,6,7,8,9,11,12,13,16,17+I F 5$ & 288.21 \\
\hline & $M$ & 1345.01 & $D L+C L 2,3,4,6,7,8,11,12,13,16,17+I F 4$ & 1345.01 \\
\hline \multirow{3}{*}{ Column } & $N$ & 8498.70 & $D L+C L($ all $)+P C L 1$ & 8498.70 \\
\hline & $Q$ & 613.73 & $D L+C L 1,2,3,4,5,7,8,9,10+P C L 1+M F 2$ & 613.73 \\
\hline & $M$ & 2035.79 & $D L+C L 8,12,13,14,15,16,17,18,19,20+P C L 1+M F 1$ & 2035.79 \\
\hline \multirow{3}{*}{$\begin{array}{l}\text { Berthing } \\
\text { component }\end{array}$} & $N$ & 923.36 & $D L+C L 1,5,6,10,11,15,16,17,18+P C L 1$ & 923.36 \\
\hline & $Q$ & 1000.00 & $D L+I F 8$ & 1000.00 \\
\hline & $M$ & 2100.08 & $D L+I F 8$ (the same to $V$ of berthing component) & 2100.08 \\
\hline \multirow{3}{*}{$\begin{array}{l}\text { Cross } \\
\text { beam }\end{array}$} & $N$ & 950.02 & $D L+C L 2,3,4,7,8,9,10,12,13,14,15,17,19,20+I F 17$ & 950.02 \\
\hline & $Q$ & 3181.94 & $\begin{array}{l}D L+C L 2,3,4,5,7,8,9,12,13,14,17,18,19,20+P C L 1+ \\
M F 7\end{array}$ & 3181.94 \\
\hline & $M$ & 6810.39 & $D L+C L 1,2,3,5,6,7,8,10,11,12,15,20+P C L 1+M F 1$ & 6810.39 \\
\hline \multirow{3}{*}{$\begin{array}{c}\text { Transverse } \\
\text { brace }\end{array}$} & $N$ & 760.82 & $D L+C L 1,6,11,16+I F 19$ & 760.82 \\
\hline & $Q$ & 441.48 & $D L+C L 2,3,4,6,7,8,9,11,12,16,17+I F 1$ & 441.48 \\
\hline & $M$ & 1238.44 & $D L+C L 2,3,4,6,7,8,9,11,12,16,17+I F 1$ & 1238.44 \\
\hline \multirow{3}{*}{$\begin{array}{l}\text { Track } \\
\text { girder }\end{array}$} & $N$ & 596.77 & $D L+C L 3,4,5,7,8,9,10,11,12,16,17+P C L 1+M F 1$ & 596.77 \\
\hline & $Q$ & 5304.57 & $D L+C L 1,2,3,4,5,6,7,8,9,10,11,15+P C L 1+M F 1$ & 5304.57 \\
\hline & $M$ & 5816.44 & $D L+C L 1,2,3,4,5,16,17,18,19+P C L 1+M F 1$ & 5816.44 \\
\hline \multirow{3}{*}{$\begin{array}{l}\text { Longitudinal } \\
\text { brace }\end{array}$} & $N$ & 159.22 & $D L+C L 1,2,3,4,5,6,7,8,9,10+P C L 1+M F 9$ & 159.22 \\
\hline & $Q$ & 441.29 & $\begin{array}{l}D L+C L 1,2,3,4,5,6,7,8,9,10,11,12,13,14,15+P C L 1+ \\
M F 1\end{array}$ & 441.29 \\
\hline & $M$ & 1143.52 & $\begin{array}{l}D L+C L 1,2,3,4,5,6,7,8,9,10,11,12,13,14,15+P C L 1+ \\
M F 1\end{array}$ & 1143.52 \\
\hline
\end{tabular}

$R S P$ : rock-socketed pile; $N$ : axial force; $Q$ : shear force; $M$ : bending moment; other acronyms are consistent with Tab. 1 ; units: kN for axial force and shear force, $\mathrm{kN} \cdot \mathrm{m}$ for bending moment.

For this paper's case study, the traditional evaluated method is applied: the combination of unfavourable load conditions of relatively special components is determined by the experience of engineers during the design process. For example, for the most unfavourable axial force of the $R S P S(2.2 \mathrm{~m})$, the most unfavourable shear force and the most unfavourable bending moment of the cross beam and track girder, according to their mechanical characteristics, the most likely combination of most unfavourable load conditions should be estimated as dead load + portal crane load + cargo load (specific lattices are unknown). The dominating loads should be self-weight and $P C L$; in terms of the calculation results by this algorithm (as shown in Tab. 4), the empirical prediction results are nearly consistent with the results produced by this paper's proposed algorithm, which further validates the correctness of the algorithm. However, due to the complexity of the frame-type wharf structure, determining the most unfavourable load combinations for other types of internal forces of piles, cross beams, longitudinal beams and other significant components (longitudinal and transverse braces) is not feasible by experience alone. Therefore, this paper develops an efficient algorithm to address this problem and proposes its adoption for similar frame-type wharf structures to determine and combine all possible loading conditions for each significant component to obtain the final most unfavourable results.

Fig. 9 to Fig. 11 show the most unfavourable results for the three representatives based on the absolute values of combined internal force presented in Tab. 4, which

include the vertical component of the RSP $(2.2 \mathrm{~m})$, the transverse component of the cross beam, and the longitudinal component of the track girder. Each figure includes the most adverse combined absolute internal force values, the detailed functional points of different load cases, and the internal force percentage pie charts of different separate load cases, which account for the most unfavourable load combinations. The predominant variable loads of the significant components in different conditions are determined according to the percentage pie figures in Fig. 9 to Fig. 11. For this paper's study, if the separate internal force value, which is determined by a certain load case that separately acts on the wharf structure model, is accounting for the maximum percentage for the most adverse combined absolute internal force, this load 
case can be considered the predominant variable load of this component.
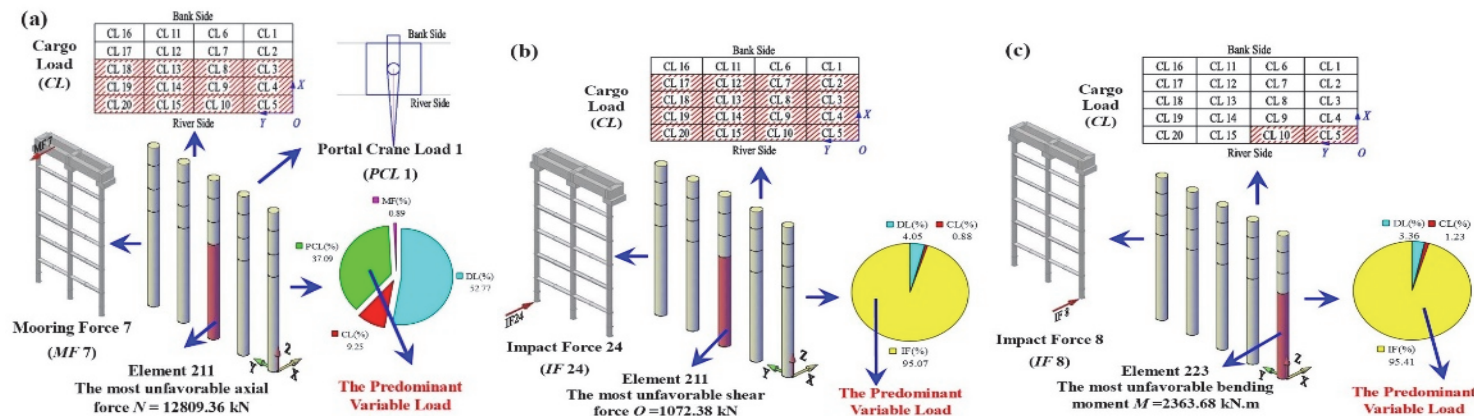

Figure 9 Most unfavourable results for the vertical components of (a) $R S P(ø 2.2 \mathrm{~m})$ - axial force $(N$, units: $\mathrm{kN})$; (b) $R S P(ø 2.2 \mathrm{~m})$ - shear force $(Q$, units: $\mathrm{kN})$; and (c) $R S P$ $(\varnothing 2.2 \mathrm{~m})$ - bending moment $(M$, units: $\mathrm{kN} \cdot \mathrm{m})$
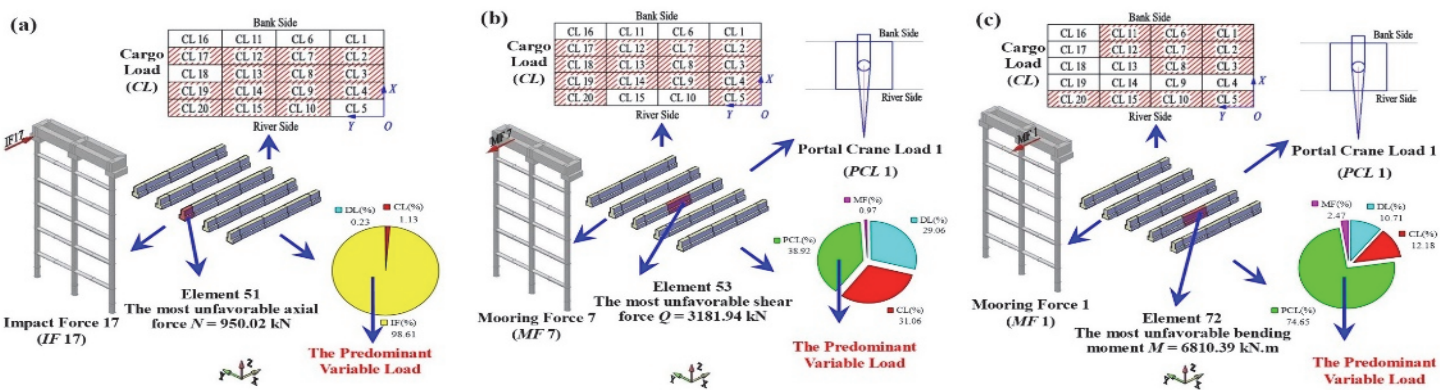

Figure 10 Most unfavourable results for the lateral components of (a) cross beam- $N$ (units: kN); (b) cross beam- $Q$ (units: $k N)$; and (c) cross beam- $M$ (units: $k N \cdot m)$
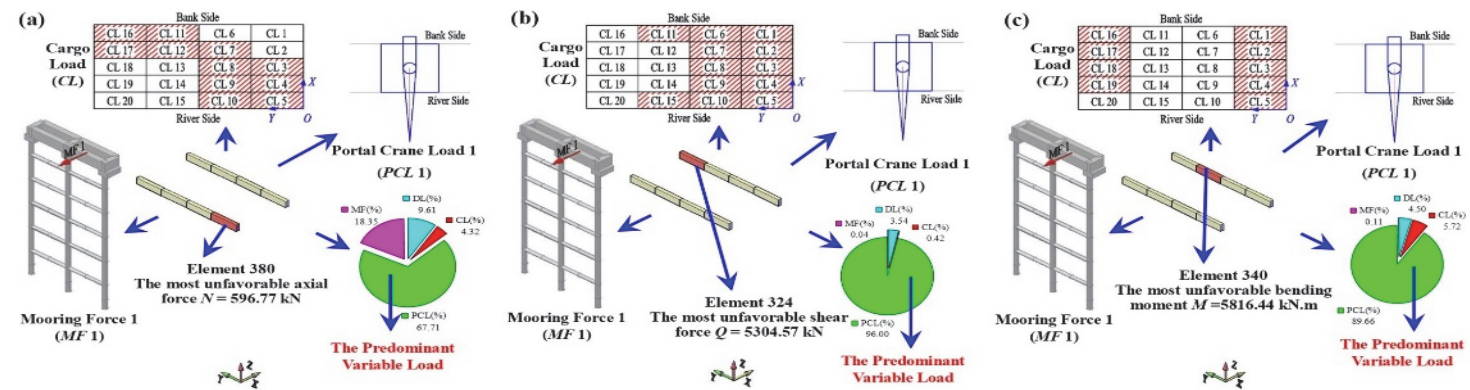

Figure 11 Most unfavourable results for the longitudinal components of (a) track girder- $N$ (units: kN); (b) track girder- $Q$ (units: $k N)$; and (c) track girder- $M$ (units: $k N \cdot m)$

\section{CONCLUSIONS}

The frame-type wharf built in the Three Gorges Reservoir of China is subjected to large water level fluctuations that exceed $30 \mathrm{~m}$. These fluctuations would cause the frame-type structure to exhibit a considerably higher number of load case combinations than traditional marine high-piled wharfs. A high-efficiency algorithm for estimating the most unfavourable load case combinations of eight significant components for multilayered frametype wharfs is presented during this paper's investigations. Based on Fig. 9 to Fig. 11, some significant conclusions are illustrated as follows:

(1) The $D L$ has a significant influence on the axial force of the vertical components (RSP $2.2 \mathrm{~m})$ and the shear force and bending moment of the horizontal components (cross beam);

(2) The predominant variable loads of these three representative components include the $P C L$ and $I F$. Although the $C L$ has a large number of load cases, it cannot be regarded as the predominant variable load due to its small values. The $M F$ is not treated as the predominant variable load for the three components of the wharf.
(3) Other predominant portal crane load cases do not appear, except for PCL 1; thus, PCL 2 and PCL 3 may not need to be considered when utilizing this paper's algorithm to estimate a similar structure when only one operation portal crane exists. The predominant variables that affect the bearing capabilities of piles and cross beams contain the $I F$ of the $H W L$ and $L W L$. When the $I F$ is considered as the predominant variable load, the load locations of different impact force load cases that act on the wharf structure are consistent with their corresponding positions with regard to the significant components' near elements. For example, the predominant variable load of the shear force for $R S P(\Phi 2.2 \mathrm{~m})$ is $I F 24$ and the load location of $I F$ 24 that acts on the berthing component of the frame-type wharf's middle bent frame (shown in Fig. 6a and Fig. 9b), which corresponds to the position of Element 211 of RSP $(\Phi 2.2 \mathrm{~m})$. The other conditions are similar in this case.

(4) PCL 1 is the predominant variable load of the axial force for the RSP and track girder, as well as the shear force and bending moment for the cross beam and track girder. IF $(H W L)$ is the predominant variable load of axial force for the cross beam. IF ( $L W L)$ is the predominant variable 
load of the shear force and bending moment for $\operatorname{RSP}(\Phi 2.2$ $\mathrm{m})$.

(5) The three predominant variable loads (PCL 1 and the impact forces $H W L$ and $L W L$ ) must be regarded as significant in the design of similar multilayered frame-type wharf structures.

In this study, the multilayered frame-type wharf structure under water level fluctuations that exceed $30 \mathrm{~m}$ in the Three Gorges Reservoir of China serves as a typical representative structure. For other similar wharf structures, the most adverse combined internal force results for a wharf's significant components and their corresponding most unfavourable load case combinations can be calculated using the algorithm proposed in this paper. Moreover, the computational results can be compared to validate and improve the final estimations, and the findings would provide powerful technical support for engineering practices.

\section{Acknowledgements}

The authors would like to appreciate the insightful and constructive comments of two anonymous reviewers. This research was supported by the Chongqing Postdoctoral Science Foundation (cstc2019jcyj-bshX0063), the Project Funded by ChinaPostdoctoral Science Foundation (2019M653824XB), and the Project of Department of Transportation of Sichuan Province (2018-B-04).

\section{REFERENCES}

[1] Veenstra, A. \& Notteboom, T. (2011). The development of the Yangtze River container port system. Journal of Transport Geography, 19(4), 772-781. https://doi.org/10.1016/j.jtrangeo.2010.09.006

[2] Notteboom, T. (2012). Challenges for container river services on the Yangtze River: A case study for Chongqing. Research in Transportation Economics, 35(1), 41-49. https://doi.org/10.1016/j.retrec.2011.11.002

[3] Bao, Y., Gao, P., \& He, X. (2015). The water-level fluctuation zone of Three Gorges Reservoir-A unique geomorphological unit. Earth-Science Reviews, 150, 14-24. https://doi.org/10.1016/j.earscirev.2015.07.005

[4] Li, L. (2015). State rescaling and national new area development in China: The case of Chongqing Liangjiang. Habitat International, 50, 80-89. https://doi.org/10.1016/j.habitatint.2015.08.009

[5] Wang, D., Wang, C., \& Miao, C. (2010). Mechanical character study on the structure of inland river overheaderection container terminal. In Proceedings of ChineseGerman joint symposium on hydraulic and ocean engineering (CG Joint 2010), Tianjin, China.

[6] Schönborn, W. (2010). Book review: Rivers of Europe. Limnologica, 278. https://doi.org/10.1016/j.limno.2010.01.001

[7] Pinter, N., Huthoff, F., Dierauer, J., Remo, J. W. F., \& Damptz, A. (2016). Modeling residual flood risk behind levees, Upper Mississippi River, USA. Environmental Science \& Policy, 58, 131-140. https://doi.org/10.1016/j.envsci.2016.01.003

[8] Vu, T. V., Kim, Y. M., \& Lee, H. E. (2015). Coupled flutter analysis of long-span bridges using full set of flutter derivatives. KSCE Journal of Civil Engineering, 20(4), 1501-1513. https://doi.org/10.1007/s12205-015-0271-x

[9] Naderian, H., Cheung, M. M. S., Shen, Z., \& Dragomirescu, E. (2015). Integrated finite strip analysis for long-span cable- stayed bridges. Computers \& Structures, 158, 82-97. https://doi.org/10.1016/j.compstruc.2015.05.031

[10] Chen, Z. W., Xu, Y. L., Xia, Y., Li, Q., \& Wong, K. Y. (2011). Fatigue analysis of long-span suspension bridges under multiple loading: Case study. Engineering Structures, 33(12), 3246-3256. https://doi.org/10.1016/j.engstruct.2011.08.027

[11] Yoo, H., Na, H. S., Choi, E. S., \& Choi, D. H. (2010). Stability evaluation of steel girder members in long-span cable-stayed bridges by member-based stability concept. International Journal of Steel Structures, 10(4), 395-410. https://doi.org/10.1007/bf03215847

[12] Kim, Y. C., Tamura, Y., \& Kim, S. (2016). Wind load combinations of typical super tall buildings. Journal of Structural Engineering, 142(1), 04015103. https://doi.org/10.1061/(asce)st.1943-541x.0001359

[13] Six, D. F. (2013). A discussion of power plant loads and load combinations. In structures congress 2013: Bridging your passion with your profession (pp. 1301-1312). Reston, USA: American Society of Civil Engineers. https://doi.org/10.1061/9780784412848.115

[14] ASCE. (1990). Minimum design loads for buildings and other structures. Reston, USA: American Society of Civil Engineers.

[15] MTPRC. (2010). Design and construction code for open type wharf on piles (JTS 167-1-2010). Beijing: Communications Press.

[16] Wang, D., Wang, C., \& Nie, Y. (2008). Study on damage style of over-erection wharf in inland river. In H. Liu, A. Deng, \& J. Chu (Eds.), Geotechnical engineering for disaster mitigation and rehabilitation, 913-919. Berlin, Heidelberg: Springer. https://doi.org/10.1007/978-3-540-79846-0_120

[17] Shen, C. \& Niu, X. (2012). Optimization of free length of high-pile wharf piles based on finite element analysis. Proceedings of international conference on civil engineering and urban planning, 444-449. Yantai, China: ASCE. https://doi.org/10.1061/9780784412435.079

[18] Xie, Y., Liu, C., Gao, S., Tang, J., \& Chen, Y. (2017). Lateral load bearing capacity of offshore high-piled wharf with batter piles. Ocean Engineering, 142, 377-387. https://doi.org/10.1016/j.oceaneng.2017.07.001

[19] Habibullah, A. \& Kalny, O. (2017). SAP 2000 home. https://wiki.csiamerica.com/display/sap2000/Home

[20] Reese, L. C. \& Van Impe, W. F. (2007). Single piles and pile groups under lateral loading. Chippenham, Wiltshire, England: Antony Rowe Ltd.

[21] MTPRC. (2010). Load code for harbour engineering (JTS 144-1-2010). Beijing: Communications Press.

[22] Burgan, H. I. \& Aksoy, H. (2018). Annual flow duration curve model for ungauged basins. Hydrology Research, 49(5), 1684-1695. https://doi.org/10.2166/nh.2018.109 


\section{Contact information:}

Linjian WU, PhD and Post-Doctor

National Engineering Research Center for Inland Waterway Regulation,

School of River and Ocean Engineering, Chongqing Jiaotong University,

66 Xuefu Road, Nan'an District, Chongqing, 400074, China

E-mail: wljabgf@126.com

Li GUAN, Master student

National Engineering Research Center for Inland Waterway Regulation, School of River and Ocean Engineering, Chongqing Jiaotong University,

66 Xuefu Road, Nan'an District, Chongqing, 400074, China

E-mail: 1065826487@qq.com

\section{Xueli JU, Master student}

National Engineering Research Center for Inland Waterway Regulation,

School of River and Ocean Engineering, Chongqing Jiaotong University, 66 Xuefu Road, Nan'an District, Chongqing, 400074, China

E-mail: juxueli97@126.com

Mingwei LIU, PhD and Professor

(Corresponding author)

National Engineering Research Center for Inland Waterway Regulation,

School of River and Ocean Engineering, Chongqing Jiaotong University,

66 Xuefu Road, Nan'an District, Chongqing, 400074, China

E-mail: mingwei_liu@126.com

Yuanfei MA, Master student

National Engineering Research Center for Inland Waterway Regulation,

School of River and Ocean Engineering, Chongqing Jiaotong University,

66 Xuefu Road, Nan'an District, Chongqing, 400074, China

E-mail: 707430336@qq.com

Erdi ABI, Ph. D and Associate professor

National Engineering Research Center for Inland Waterway Regulation,

School of River and Ocean Engineering, Chongqing Jiaotong University,

66 Xuefu Road, Nan'an District, Chongqing, 400074, China

E-mail: abierdi@163.com 